\title{
A Novel Approach to Study Real-Time Dynamic Optimization Analysis and Simulation of Complex Mine Logistics Transportation Hybrid System with Belt and Surge Links
}

\author{
Bai Xiao-ping, Zhao Yu-hong, and Liu Ya-nan \\ System Engineering Research Institute, School of Management, Xi'an University of Architecture and Technology, Xi'an 710055, China \\ Correspondence should be addressed to Bai Xiao-ping; xxppbai@126.com
}

Received 2 September 2014; Accepted 16 January 2015

Academic Editor: Ivan Area

Copyright (c) 2015 Bai Xiao-ping et al. This is an open access article distributed under the Creative Commons Attribution License, which permits unrestricted use, distribution, and reproduction in any medium, provided the original work is properly cited.

\begin{abstract}
The mine logistics transportation system with belt and surge links is often formed by a complex hybrid dynamic system that consists of continuous and discrete links, and these parts can have the complex changes along with the mining engineering going on. Studying the hybrid system with belt and surge links to fully realize its beneficial functions is very significant. Until now, there have been many references studying the logistics transportation hybrid system with belt and surge links, and many concepts about it have been set up. However, in these references, complicated real-time dynamic changes of the hybrid system usually is studied. This paper presents a novel approach to study real-time dynamic optimization analysis and simulation problems of complex mine logistics transportation hybrid system, which can be used to make optimization design for this kind of complex hybrid system. The proposed method considered expressly complicated real-time dynamic changing of the hybrid system comparing with some existing references and can solve some optimization design problems of the hybrid system. In addition, this paper used statistical data of a real logistics transportation system with belt and surge bin on simulation and gets some useful conclusions. The application result shows that the presented method is valid.
\end{abstract}

\section{Introduction}

In complex mine logistics belt transportation system, surge links are often set. The mine logistics transportation system with belt and surge links is often formed by a complex hybrid dynamic system. By setting surge bin, links behind bin can continue transporting logistics of bin when links ahead of bin are in failure; on the other hand, links ahead of bin can continue transporting logistics to bin when links behind bin are in failure. Therefore, setting surge bin can reduce the interacting of links ahead and behind bin to improve reliability of the whole hybrid transportation system. The block diagram of this hybrid system is shown in Figure 1.

Where 1 is links ahead of bin, $h$ is surge bin, and 2 are links behind bin. The function of surge bin can be discussed as follows.

(1) By setting surge bin, links behind bin can continue transporting logistics of bin when links ahead of bin are in failure; on the other hand, links ahead of bin can continue transporting logistics to bin when links behind bin are in failure. Therefore, setting surge bin can reduce the interacting of links ahead and behind bin to improve reliability of the whole transportation system.

(2) Setting surge bin can buffer transporting flows to keep the uniformity, that is, can cut down high transporting flows and can fill up low transporting flows.

(3) By setting surge bin, logistics can be classified and neutralized. So quality problems of logistics can be solved.

\section{Some Related Studying References}

Until now, there have been many references studying the hybrid system with belt and surge links, and many concepts about it have been set up. In 1950s, the transportation system 


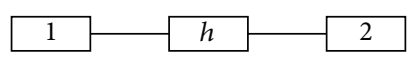

FIgURE 1: The flow chart of the surge bin system.

with surge bin was named as soft or flexibility connecting system by Professor J. Kerp that comes from Poland. He discussed the influencing function of surge bin for the transportation system but lacked quantificational analyzing. In [1], a model to simulate the existing conveyor belt haulage system at an underground coal mine in Southern Utah, USA, was presented. By recording spillage and belt stoppage statistics for the simulated flow, belt and surge capacities were evaluated. Comparison of results for the belt system with and without a surge bin showed that the addition of a surge bin to the system increased production by $13.2 \%$. In [2], computer simulation method was used to analyze how surge bin improves the validity of system, and the method calculating the validity of soft connecting system under mine well was also presented. In [3], stochastic process and linear extension methods were used to modeling and analyzing reliability of surge bin system. In [4], authors made use of the theory of queuing system with storage bin to analyze the rational capacity of surge bin. In [5], the author calculated, respectively, validity of two series systems: one included surge bin and links ahead of bin and the other included surge bin and links behind bin, shown in Figure 2 . Then the author presented such a point that the theoretical validity of soft connecting system should not be greater than the minimum value of above two validities. In [6], the author presented a reliability model about surge bin system on the premise of machine-electrical failures of bin were not considered, shown in Figure 3; that is, surge bin is in parallel with links behind bin and then is in series with links ahead of bin. In [7], a computer simulation model of reliability of mining haulage system with two ore bins was established. In [8], based on a new definition of surge bin's failure, the reliability logical relationship between the surge bin and its preceding link and following-up link has been determined, and the corresponding reliability model has been set up in the paper. In [9], in view of real situations in multilevel underground mines, a computer simulation model of reliability of mining haulage system with two ore bins has been established. In [10], the purposes of data acquisition for belt conveyer include equipment validation, condition monitoring, and long-term data trending; verification of theoretical calculations and forensic engineering are discussed. In [11], a knowledge-based expert system for belt conveyor monitoring and its maintenance decision-making procedures have been developed to overcome some problems. In [12], the author develops a new heuristic method and we propose an integer programming model for the storage problem; the algorithm was applied in the case of unlimited number of bins. In [13], a discrete element model (DEM) (particle flow code, PFC3D) was constructed to simulate vibration of bulk solids in a bin filled with soybeans; the vibration frequencies and amplitudes of individual particles were determined from simulated particle velocities and displacements at different excitation frequencies and amplitudes. In [14], a

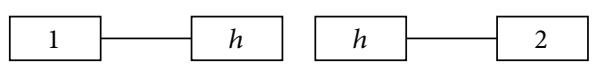

(a)

(b)

FIGURE 2: The proposed roughly reliability model diagram (a) and diagram (b) of the hybrid system in [5].

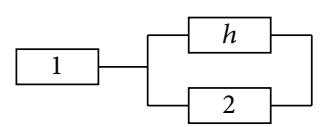

FIGURE 3: The reliability model diagram of the hybrid system in [6] on ignoring machine electrical failures of bin.

two-dimensional particulate model is developed to predict vibration-induced loads in bulk solids storage bins; the model assumes that bulk solids consist of equal-sized spherical particles that form a quasihexagonal structure. In [15], a predictive model is developed for arch destruction during vertical vibration in storage bins for cohesive bulk solids and so forth [16-19].

In these references, complicated real-time dynamic changes of this hybrid system usually were not studied. For example, when links behind bin are in failure, links ahead of bin can continue transporting logistics to bin, but this function is limited and will disappear once full bin state occurs; on the other hand, when links ahead of bin are in failure, links behind bin can continue transporting logistics of bin, but this function is also limited and will disappear once empty bin state occurs. In addition in practice when reliability of surge bin itself is low, sometimes setting surge bin not only cannot improve reliability of whole system but also can reduce reliability of it. This paper emphasized these factors and presents a novel approach to study real-time dynamic optimization analysis and simulation of complex mine logistics transportation hybrid system.

\section{Real-Time Dynamic Optimization Analysis and Simulation Method for Transportation Hybrid System with Belt Surge Bin}

3.1. The Optimization Analysis and Simulation Method Introduction. This paper emphasized these factors and presents a new real-time dynamic computer simulation method to solve some problems about optimization design of complex mine logistics transportation hybrid system with belt and surge links.

For surge bin, the varying of inputting logistics, outputting logistics, and reserving logistics in the bin are continuous; in this case time step length simulation method is usually adopted. On simulation this paper considered surge bin, links ahead of bin, and links behind bin as a whole. Firstly, suppose bin capacity is big enough, keep the surge bin system to work on condition that there is not bin capacity limit, and count frequencies of various storage logistics levels during whole simulation period. Various storage logistics levels are measured by certain logistics value scopes, such as ranging between 0 and 50 tons. The normalized cumulative 
TABLE 1: The real-time dynamic control methods of simulated system.

\begin{tabular}{|c|c|c|}
\hline \multicolumn{2}{|c|}{ All kinds of states } & Real-time dynamic simulation control methods \\
\hline \multirow{4}{*}{ For entrance of bin } & Links ahead of bin and bin itself are all in working state & Allowing logistics to be transported to bin \\
\hline & Links ahead of bin are in failure & Not allowing logistics to be transported to bin \\
\hline & Bin itself is in mechanical and electrical failure states & Not allowing logistics to be transported to bin \\
\hline & $\begin{array}{l}\text { Links ahead of bin are normal, but bin itself is in empty bin } \\
\text { state }\end{array}$ & Allowing logistics to be transported to bin \\
\hline \multirow{4}{*}{ For exit of bin } & Links behind bin and bin itself are all in working state & Allowing logistics to be transported out of bin \\
\hline & Links behind bin are in failure state & Not allowing logistics to be transported out of bin \\
\hline & Bin itself is in mechanical and electrical failure states & Not allowing logistics to be transported out of bin \\
\hline & Bin itself is in empty bin state & Links behind bin must stop operating. \\
\hline
\end{tabular}

frequency values can be thought as approximate service reliability of the corresponding bin capacity level upper boundary, such as normalized cumulative frequencies value $30 \%$ ranging between 0 and 50 tons which can be thought as approximate service reliability of bin capacity being 50 tons. Because $30 \%$ can be thought as the probability of storage logistics located in range between 0 and 50 tons when bin capacity is big enough, there are $70 \%$ possibilities those storage logistics located outside ranging between 0 and 50 tons. In practice, if bin capacity is designed to be 50 tons, then there is $70 \%$ possibility that surge bin is in the full bin state.

\subsection{Real-Time Dynamic Optimization Analyzing of Simulated} System. For emphasizing real-time dynamic changes of the surge bin system, this paper analyzed all kinds of different failure states of surge bin. In practice, these states can be summarized as follows. Firstly, inputting and outputting logistics of surge bin need to be realized by some mechanical and electrical devices, so surge bin can be in mechanical and electrical failure states; secondly, surge bin can be in the empty bin state; thirdly, surge bin can be in the full bin state. Because supposing bin capacity is big enough in the simulation method selected for this paper, that is, full bin state does not exist, there are only two kinds of failure states, which include mechanical and electrical failure states and empty bin state. On simulation the entrance and exit of bin need to be considered, respectively.

There are some following kinds of states in the entrance of bin. (1) Links ahead of bin and bin itself are all in working state and logistics can be transported normally to bin by the entrance of bin; (2) links ahead of bin are in failure, and logistics cannot be transported normally to bin; (3) bin itself is in mechanical and electrical failure states, and logistics cannot be transported normally to bin; (4) links ahead of bin are normal, but bin itself is in empty bin state, and logistics can be transported normally to bin by the entrance of bin.

In the same way, there are also some states in the exit of bin. (1) Links behind bin and bin itself are all in working state, and logistics can be transported normally out of bin; (2) links behind bin are in failure state, and logistics cannot be transported normally out of bin; (3) bin itself is in mechanical and electrical failure states, and logistics cannot be transported normally out of bin; (4) bin itself is in the empty bin state, and links behind bin must stop operating. Links ahead of bin and links behind bin can be controlled in a simulation program according to the above different cases. Real-time dynamic control methods of the simulated system are shown in Table 1.

3.3. Numerical Analysis and Processing of Random Variables for Simulation. For reflecting random varying of the surge bin system, the paper selected some random variables, which include inputting logistics variable, outputting logistics variable, the working time and failure time variables of links ahead of bin, the working time and mechanical and electrical failure time, and empty bin time variables of bin, the working time and failure time variables of links behind bin.

For simulation, it is necessary to collect a lot of practical sample data of each random variable and to study their probability distribution rule. Detailed numerical analysis steps of simulated random variables are shown as follows.

(1) Dividing Sample Value into Groups. This paper finds out the maximum value $x_{\max }$ and the minimum value $x_{\min }$; let $a$ be slightly less than $x_{\min }$ and $b$ slightly larger than $x_{\max }$. It divides the interval $[a, b]$ into some unequal subinterval and gets some partition points $t_{i}$ by

$$
a=t_{0}<t_{1}<t_{2} \cdots<t_{i-1}<t_{i}<\cdots<t_{m}=b .
$$

The group width is the equal value, shown as

$$
t_{i}-t_{i-1}=\frac{b-a}{m} \quad(i=1,2, \ldots, m),
$$

where $m$ is the group number, which is determined by the sample size $n$, and $m$ value is also small when the value of sample size $n$ is small and vice versa. The group number $m$ can also be determined by the empirical formula, such as

$$
m=1+3.22 \ln (n) .
$$

(2) Calculating the Frequency Number and Frequency of Grouped Data. This paper calculates the number of sample value in the interval $\left[t_{i-1}, t_{i}\right]$; it is called as the frequency number $V_{i}(i=1,2, \ldots, m)$. The frequency $f_{i}$ of sample value in the interval $\left[t_{i-1}, t_{i}\right]$ can be shown as

$$
f_{i}=\frac{V_{i}}{n} \quad(i=1,2, \ldots, m),
$$




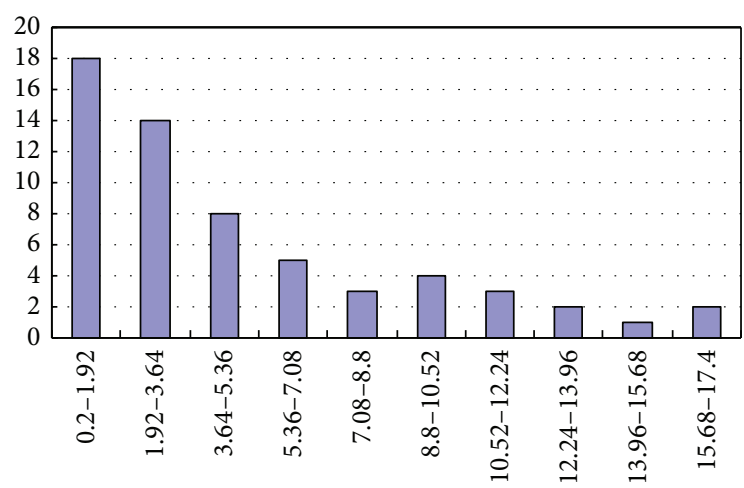

FIGURE 4: The schematic diagram of a kind of frequency distribution histogram.

where $f_{i}$ can be expressed approximately as the probability of sample value falling on the interval $\left[t_{i-1}, t_{i}\right]$; it can be shown as

$$
f_{i} \approx p\left(t_{i-1} \leq X<t_{i}\right) \quad i=1,2, \ldots, m .
$$

If the probability density function of the random variable $X$ is $f(x)$, so

$$
f_{i} \approx \int_{t_{i-1}}^{i} f(x) d x \quad i=1,2, \ldots, m .
$$

(3) Drawing the Frequency Distribution Histogram. The frequency distribution histogram consists of a series of rectangles whose widths are defined by the equal group width $\left(t_{i}-t_{i-1}\right)$ and whose heights are determined by

$$
h_{i}=\frac{f_{i}}{t_{i}-t_{i-1}} .
$$

The schematic diagram of a kind of frequency distribution histogram is shown as Figure 4.

Where the area of each rectangle can be calculated by

$$
\frac{f_{i}}{t_{i}-t_{i-1}}\left(t_{i}-t_{i-1}\right)=f_{i} \approx \int_{t_{i-1}}^{t_{i}} f(x) d x .
$$

If drawing a curve, let it nearly pass through the upside of every rectangle, so one can roughly judge which probability density type is matched with the simulated random variable and get the approximate probability density curve of simulated random variable.

(4) Parameter Estimation. This paper uses the maximum likelihood estimation method to make parameter estimation; the method is described as follows.

Supposing the type $f\left(x_{n}, \theta\right)$ of probability density function of the simulated random variable $X$ is known, $\theta$ is an unknown parameter and $\left(x_{1}, x_{2}, \ldots, x_{n}\right)$ is a group sample value of the population $X$, their joint probability density can be shown as

$$
f\left(x_{1}, x_{2}, \ldots, x_{n}, \theta\right)=\prod_{i=1}^{n} f\left(x_{i}, \theta\right) .
$$

It is the function including the unknown parameter $\theta$, which can be shown as

$$
L_{i}=L\left(x_{1}, x_{2}, \ldots, x_{n}, \theta\right)=\prod_{i=1}^{n} f\left(x_{i}, \theta\right) .
$$

The $L_{i}$ is called likelihood function.

According to the maximum likelihood estimation method, if there is an estimated value $\widehat{\theta}$ of the unknown parameter $\theta$, when $\theta$ equals $\hat{\theta}$, the likelihood function $L\left(x_{1}, x_{2}, \ldots, x_{n}, \theta\right)$ satisfies

$$
L\left(x_{1}, x_{2}, \ldots, x_{n}, \theta\right)=\max .
$$

Then $\widehat{\theta}$ is called the maximum likelihood estimation value of the unknown parameter $(\theta)$. According to the Lagrange extreme method, $\hat{\theta}$ can be gotten by

$$
\frac{d}{d \theta} L=0
$$

(5) $x^{2}$ Testing. The probabilistic distribution gotten by the frequency distribution histogram and the maximum likelihood parameter estimation method must be tested to be used.

This paper uses $x^{2}$ test method. This method uses $n$ observed values $x_{1}, x_{2}, \ldots, x_{n}$ to test the hypothesis $\mathrm{H}_{0}$ : the distribution function of the simulated random variable is $F(x)$. By $F(x), x$-axis is divided into $k$ disjointed intervals $\left(a_{i}, a_{i+1}\right), i=1,2, \ldots, k$, where $k$ is generally from 7 to 14 . The probability $P_{i}$ of observed value falling to the interval $\left(a_{i}, a_{i+1}\right)$ is shown as

$$
P_{i}=F\left(a_{i+1}\right)-F\left(a_{i}\right)=p\left(a_{i}<x \leq a_{i+1}\right) .
$$

The $P_{i}$ can be calculated by the theoretical distribution function $F(x)$; the theoretical frequency number can be calculated as $n p_{i}$.

On the other hand, the practical frequency number $V_{i}(i=1,2, \ldots, k)$ can be gotten by analyzing the number of sample value $\left(x_{1}, x_{2}, \ldots, x_{n}\right)$ falling into the interval $\left(a_{i}, a_{i+1}\right)$. If the overall theoretical frequency number is close to the practical frequency number in every interval range, then the hypothesis $\mathrm{H}_{0}$ is accepted, or it is rejected.

The formula of testing whether or not the hypothesis $\mathrm{H}_{0}$ is correct is

$$
\chi^{2}=\sum_{i=1}^{k} \frac{\left(V_{i}-n p_{i}\right)^{2}}{n p_{i}}
$$

According to Pearson's theorem, if the following formula is satisfied, then the hypothesis $\mathrm{H}_{0}$ is rejected, or it is accepted:

$$
\chi^{2}>\chi_{\alpha}^{2}(K-r-1),
$$

where $r$ is degree of freedom, which is the number of estimated parameter. $\chi^{2}$ is calculated by the formula (15). $\chi_{\alpha}^{2}(K-r-1)$ is gotten by lookup $\chi^{2}$ distribution table. 
(6) Practical Analyzing and Calculating of Simulated Random Variables. According to detailed steps from (1) to (6), this paper gets some following calculating results.

The inputting logistics of bin is a negative exponential distribution random variable, whose distributed parameter is $83.75 \mathrm{t} / 10 \mathrm{~min}$; the outputting logistics of bin is a normal distribution random variable, whose distributed parameters have two values. The mean is $323 \mathrm{t} / 10 \mathrm{~min}$, and the variance is $10.34 \mathrm{t} / 10 \mathrm{~min}$.

(7) Producing a Series of Random Variables for Simulation. On simulation processing, this paper produces a series of random variables for inputting logistics of bin according to the following formula:

$$
y_{i}=-\frac{1}{\lambda_{1}} \ln \left(r_{i}\right),
$$

where $\lambda_{1}$ is the distributed parameter inputting logistics of bin, whose value is $83.75 \mathrm{t} / 10 \mathrm{~min} . r_{i}$ is uniformly distributed random number in the interval $(0,1)$.

For outputting logistics of bin, this paper produces random variables according to the following formula:

$$
Z_{i}=\mu+\sigma\left(r_{1}+r_{2}+r_{3}+\cdots+r_{12}-6\right),
$$

where $\mu$ is the mean of outputting logistics of bin, whose value is $323 \mathrm{t} / 10 \mathrm{~min}$, and $\sigma$ is the variance of outputting logistics of bin, whose value is $10.34 \mathrm{t} / 10 \mathrm{~min} .\left(r_{1}, r_{2}, r_{3}, \ldots, r_{12}\right)$ are 12 uniformly distributed random numbers in the interval $(0,1)$.

3.4. Simulated Process. This paper firstly analyzed all kinds of cases in the exit of surge bin and counted tons of outputting logistics during the simulation period. The difference of inputting logistics and outputting logistics can be thought as storage logistics value in the bin. If the residual space of bin cannot contain inputting logistics in a time step length, then the entrance of bin and links ahead of bin should stop operating. These can be realized in the simulation program.

By the above analysis, this paper created the corresponding simulation program; the program flow chart is shown in Figure 5.

\section{Corresponding Simulation Case Study}

This paper takes example for the hybrid system with belt and surge bin of a real surface mine at the north of China; the transportation flow chart of this system is shown in Figure 6. On simulation selected time step length is 10 minutes. At 6:00 in the morning begin simulation, analyze statistically, and count inputting logistics, storage capacity, and outputting logistics per time step length.

After a day simulation was completed; the biggest storage capacity of bin and production capacity could be gotten by simulation program; for this instance, the outputting result from the program simulation for 50 days was shown in Table 2.

Scope levels of storage capacity values of bin were counted at intervals of 50 tons, so frequencies or days of

\begin{tabular}{|c|c|c|}
\hline Day ID & $\begin{array}{c}\text { The biggest daily } \\
\text { capacity } \\
\text { of bin (tons) }\end{array}$ & $\begin{array}{l}\text { Daily production } \\
\text { capacity (tons) }\end{array}$ \\
\hline 1 & 11.34 & 4139.76 \\
\hline 2 & 37.09 & 5817.63 \\
\hline 3 & 98.55 & 6508.47 \\
\hline 4 & 309.32 & 5411.36 \\
\hline 5 & 167.32 & 6547.41 \\
\hline 6 & 25.78 & 5344.06 \\
\hline 7 & 351.91 & 6843.42 \\
\hline 8 & 125.06 & 5801.39 \\
\hline 9 & 105.47 & 6259.13 \\
\hline 10 & 36.22 & 5620.90 \\
\hline 11 & 322.15 & 6396.39 \\
\hline 12 & 141.98 & 6884.21 \\
\hline 13 & 142.84 & 5806.76 \\
\hline 14 & 26.36 & 6807.03 \\
\hline 15 & 32.18 & 5124.21 \\
\hline 16 & 370.61 & 6302.12 \\
\hline 17 & 30.04 & 5454.35 \\
\hline 18 & 4.82 & 5945.13 \\
\hline 19 & 186.81 & 4863.64 \\
\hline 20 & 7.89 & 4848.72 \\
\hline 21 & 80.49 & 6478.09 \\
\hline 22 & 25.03 & 6014.48 \\
\hline 23 & 34.26 & 6234.89 \\
\hline 24 & 281.28 & 7428.29 \\
\hline 25 & 107.69 & 7031.93 \\
\hline 26 & 375.79 & 6333.29 \\
\hline 27 & 53.20 & 6021.81 \\
\hline 28 & 153.00 & 5734.36 \\
\hline 29 & 57.44 & 5555.04 \\
\hline 30 & 70.12 & 6338.14 \\
\hline 31 & 247.69 & 6571.02 \\
\hline 32 & 23.11 & 5609.13 \\
\hline 33 & 35.10 & 6044.89 \\
\hline 34 & 23.69 & 5810.80 \\
\hline 35 & 180.82 & 7357.17 \\
\hline 36 & 98.62 & 6070.38 \\
\hline 37 & 83.31 & 5997.65 \\
\hline 38 & 115.29 & 6554.00 \\
\hline 39 & 42.15 & 5248.07 \\
\hline 40 & 114.77 & 6270.45 \\
\hline 41 & 115.57 & 6406.35 \\
\hline 42 & 125.21 & 5323.44 \\
\hline 43 & 93.70 & 6007.87 \\
\hline 44 & 92.14 & 6461.57 \\
\hline 45 & 25.56 & 6548.04 \\
\hline 46 & 66.38 & 6353.29 \\
\hline 47 & 99.41 & 5588.00 \\
\hline 48 & 178.58 & 5592.99 \\
\hline 49 & 24.56 & 5594.37 \\
\hline 50 & 77.08 & 6117.00 \\
\hline
\end{tabular}

TABLE 2: The first output result of the simulation program.

various storage logistics levels occurring could be calculated by Table 1 and then cumulative frequencies are counted; finally approximate service reliability of the corresponding 


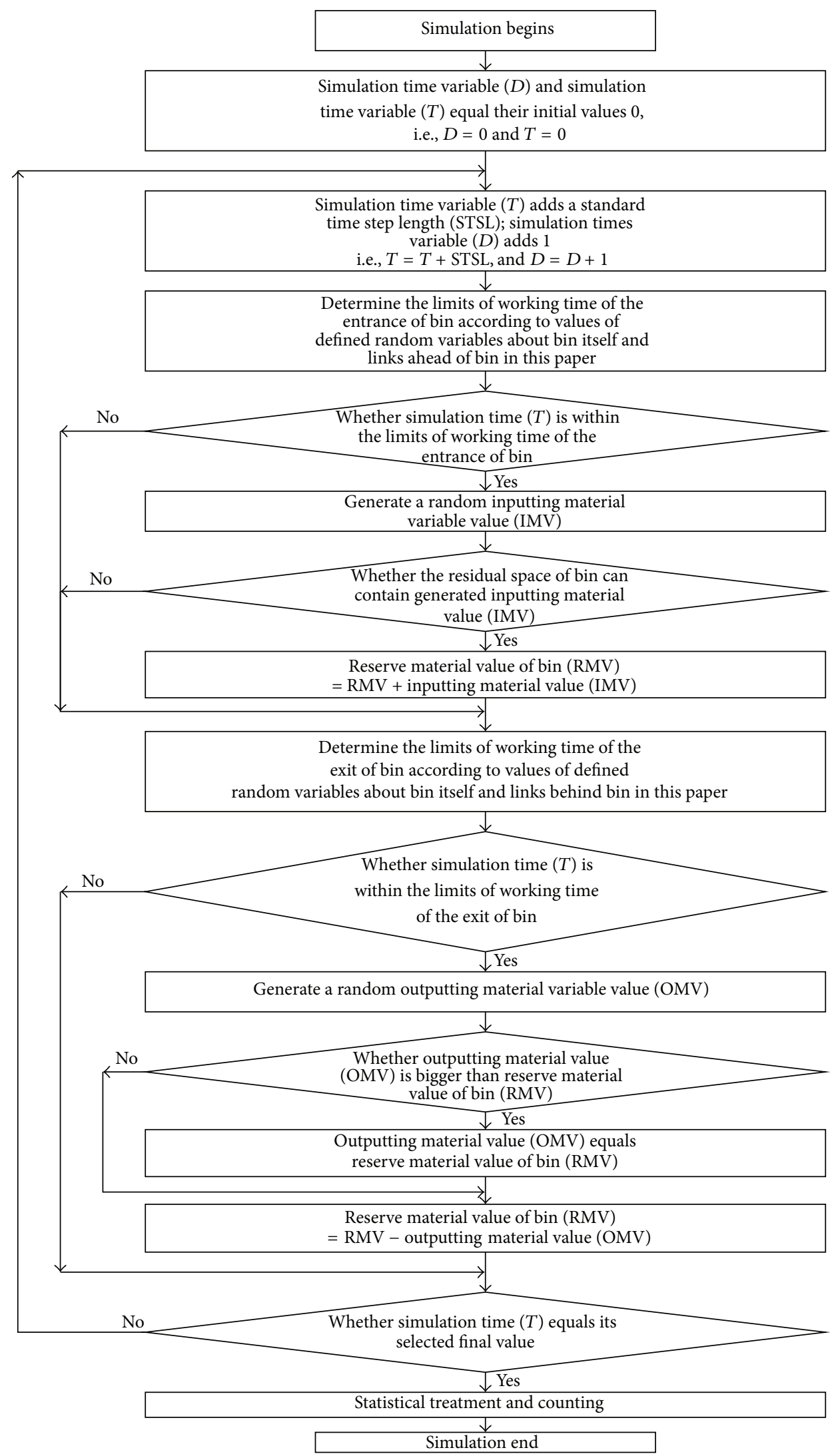

FIGURE 5: The flow chart of the simulation program. 


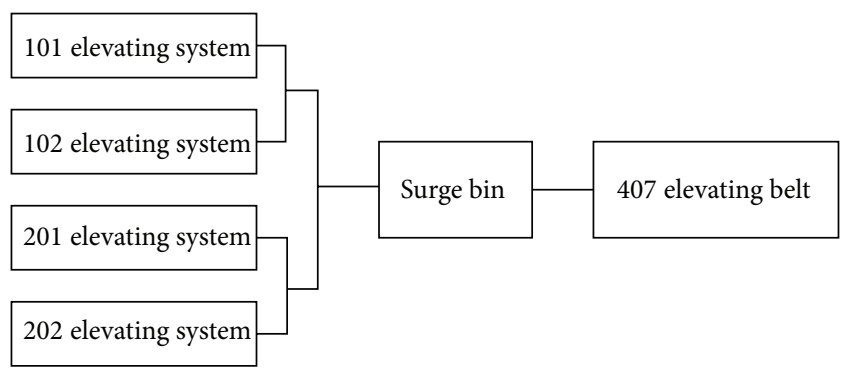

FIGURE 6: The flow chart of a real hybrid system with belt and surge bin.

TABLE 3: The second output result of the simulation program.

\begin{tabular}{ccccc}
\hline ID & $\begin{array}{c}\text { Scopes } \\
\text { (tons) }\end{array}$ & Frequencies & $\begin{array}{c}\text { Cumulative } \\
\text { frequencies }\end{array}$ & $\begin{array}{c}\text { Service } \\
\text { reliability }\end{array}$ \\
\hline 1 & $(0,50)$ & 17 & 17 & 0.34 \\
2 & $(50,100)$ & 12 & 29 & 0.58 \\
3 & $(100,150)$ & 9 & 38 & 0.76 \\
4 & $(150,200)$ & 5 & 43 & 0.86 \\
5 & $(200,250)$ & 1 & 44 & 0.88 \\
6 & $(250,300)$ & 1 & 45 & 0.90 \\
7 & $(300,350)$ & 2 & 47 & 0.94 \\
8 & $(350,400)$ & 3 & 50 & 1.00 \\
\hline
\end{tabular}

bin capacity level upper boundary could be counted by the formula (18), shown in Table 3:

$$
\rho=\frac{\sum f_{i}}{N}
$$

where $f_{i}$ is frequency of bin capacity within the scopes of $T_{i-1}$ and $T_{i}$ and $N$ is simulation total days.

As an application case, by Table 3, the service reliability of bin can attain $86 \%$ or better as long as capacity of surge bin is designed as $200 \mathrm{t}$. The total production in this case can also be gotten by calculating the corresponding data that the biggest storage capacity of bin is less than $200 \mathrm{t}$ in Table 2. Other cases are similar to this analysis method.

\section{Conclusions}

In some complex belt transport system, surge links are often set, such as coal bin, ore bin, and storage bin in mine and other transport systems. The mine logistics transportation system with belt and surge links is often formed by a complex hybrid dynamic system. Setting surge bin is an effective and usually selected method for improving reliability of the complex logistics transportation network system. In practice, beneficial functions of the surge bin usually cannot be fully realized because complexities of the surge bin system itself. Therefore, there are many significant problems that need to be studied for complex logistics transportation system with surge parts.

By emphasizing complicated real-time dynamic changes of the hybrid system with belt and surge links and all kinds of different failure states of surge bin, which include mechanical and electrical failure states, empty bin, and full bin comparing with other references, this paper presents a novel approach to study real-time dynamic optimization analysis and simulation of complex mine logistics transportation hybrid system and created the corresponding simulation programs for practical hybrid system. The proposed numerical analysis and simulation method including a computer program can solve some optimization design problems of the complex hybrid system with belt and surge parts and can be used to instruct effectually practical production of complex mine logistics transportation hybrid system with belt surge links.

\section{Conflict of Interests}

The authors declare that there is no conflict of interests regarding the publication of this paper.

\section{Acknowledgments}

This work was supported in part by NSFC (National Nature Science Foundation of China) (59874019), Shanxi Province Education Department Research Project (12JK0803), and Shanxi Province Key Discipline Construction Special Fund Subsidized Project (E08001).

\section{References}

[1] R. L. McNearny and Z. Nie, "Simulation of a conveyor belt network at an underground coal mine," Mineral Resources Engineering, vol. 9, no. 3, pp. 343-355, 2000.

[2] T. Zuzhang, "The reliability of soft connection transportation system under mine well," Journal of China Coal Society Reliability, vol. 18, no. 1, pp. 27-32, 1993.

[3] Y. Wang and R. Wang, "The exact solution of the basic reliability model about soft connection mine well production line," Journal of China Coal Society, vol. 20, no. 4, pp. 17-20, 1995.

[4] M. Y. Lu, D. X. Zhang, and Q. X. Cai, "Rational capacity setting of the storage bin at open-pit crushing station," Metal Mine, no. 9, pp. 5-7, 2001.

[5] Z. Tang, "A method calculating validity of soft connection transportation system under mine well," in Proceedings of the 5th China Conference of Mine System Engineering, pp. 25-28, 1990.

[6] S. Yu, Reliability Engineering Introduction in Coal Mines, Coal Industrial Press, Beijing, China, 1988.

[7] C. Liu, Y. Jiao, and D. Liu, "Reliability simulation of mining haulage system with soft link," The Chinese Journal of Nonferrous Metals, no. 2, pp. 24-33, 1997.

[8] Q. Cai, "Reliability design and analysis of transportation system with a surge bin in mines," Journal of Fuxin Mining Institute (Natural Science Edition), no. 1, pp. 20-23, 1997.

[9] C. Liu, Y. Jiao, and D. Liu, "Reliability simulation of mining haulage system with soft link," The Chinese Journal of Nonferrous Metals, vol. 7, no. 2, pp. 24-33, 1997.

[10] D. Kruse, "Data aquisition techniques and measurement equipment for belt conveyors," Bulk Solids Handling, vol. 26, no. 2, pp. 116-122, 2006.

[11] Y. Pang and G. Lodewljks, "Knowledge-based maintenance decision-making for large-scale belt conveyor systems," Bulk Solids Handling, vol. 26, no. 1, pp. 32-39, 2006. 
[12] M. Salma and F. Ahmed, "Three-dimensional bin packing problem with variable bin length application in industrial storage problem," in Proceedings of the 4th International Conference on Logistics (LOGISTIQUA '11), pp. 508-513, Hammamet, Tunisia, May-June 2011.

[13] C. Liu, Q. Zhang, and Y. Chen, "Discrete element simulations of vibration characteristics of bulk grain in storage bins," Transactions of the ASABE, vol. 53, no. 5, pp. 1653-1659, 2010.

[14] X. Cheng and Q. Zhang, "A particulate model for predicting vibration-induced loads in bulk solids storage bins," Transactions of the ASABE, vol. 49, no. 3, pp. 759-765, 2006.

[15] T. Ge and Q. Zhang, "Development of a predictive model for arch destruction by vibration in storage bins for cohesive bulk solids," Transactions of the American Society of Agricultural Engineers, vol. 48, no. 5, pp. 1905-1910, 2005.

[16] Z. Ying and Y. Liu, "A new approach for reliability evaluation of multi-state device systems with link-capacities," Advances in Systems Science and Applications, vol. 4, no. 4, pp. 670-676, 2004.

[17] H. Zhou and Z. Li, "Research on inventory simulation system in distribution," Advances in Systems Science and Applications, vol. 2, no. 2, pp. 217-221, 2002.

[18] T. Li, B. Guo, and R. Deng, "Intelligent control of some uncertainty complex system," Advances in Systems Science and Applications, vol. 4, no. 2, pp. 231-237, 2004.

[19] J. B. Oosthuizen and G. S. Esterhuizen, "Evaluation of three rock breaker layouts for mechanized block cave mining," Journal of The South African Institute of Mining and Metallurgy, vol. 97, no. 6, pp. 269-273, 1997. 


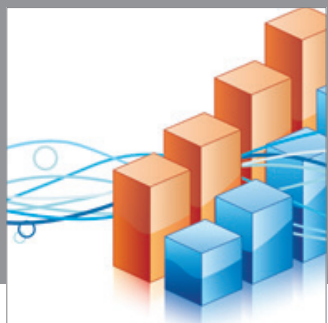

Advances in

Operations Research

mansans

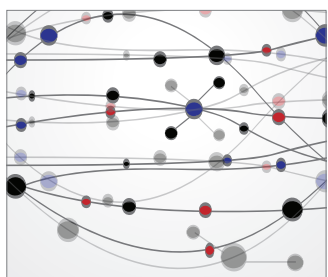

The Scientific World Journal
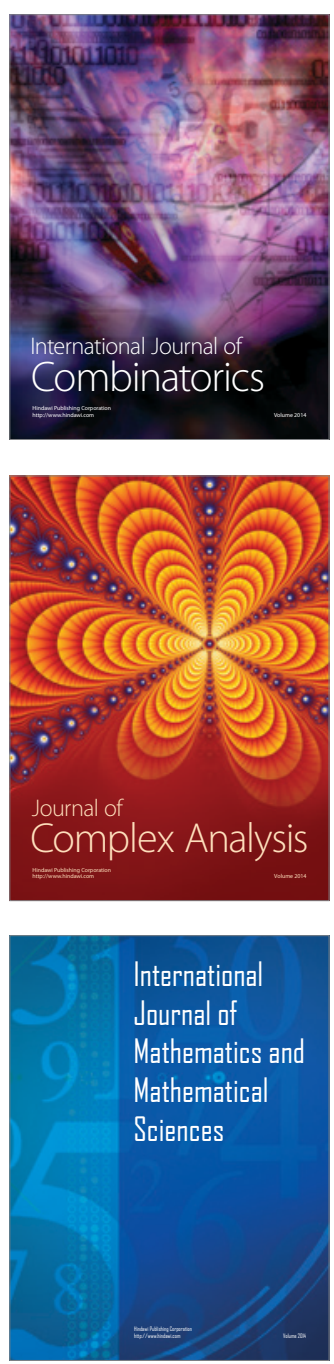
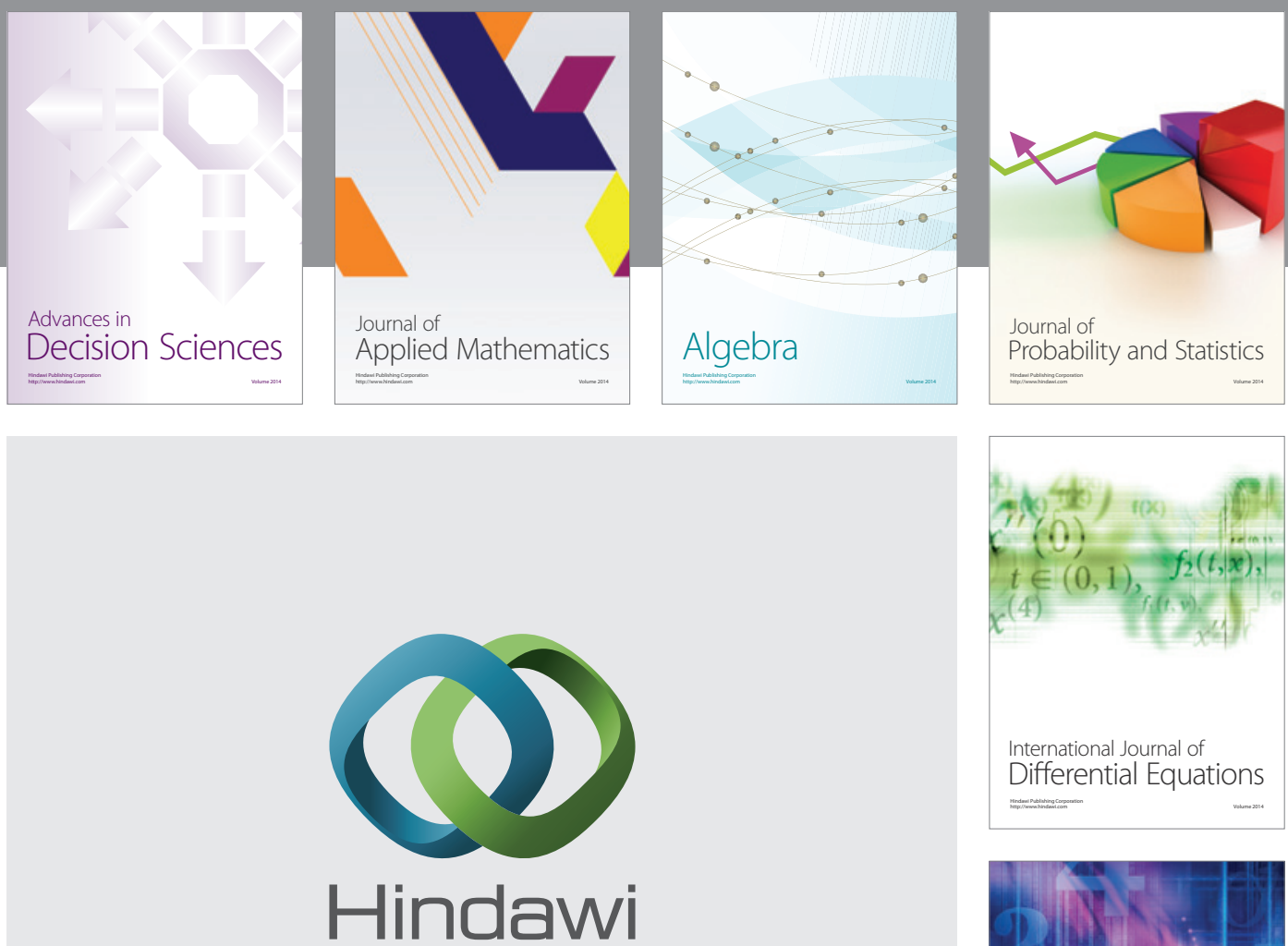

Submit your manuscripts at http://www.hindawi.com
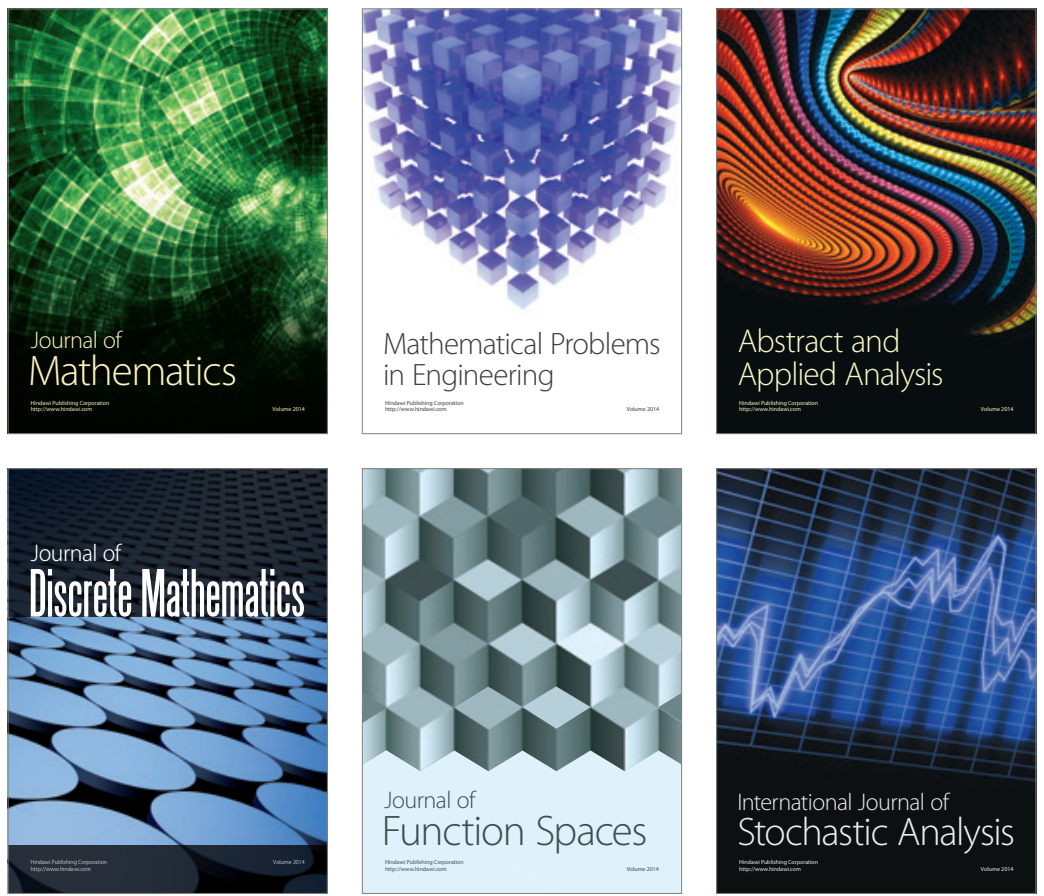

Journal of

Function Spaces

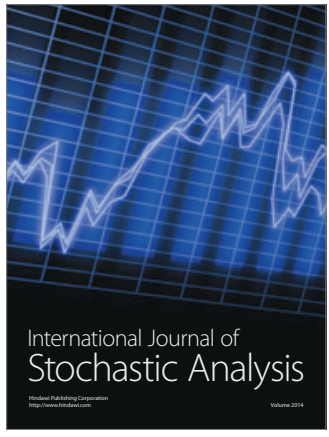

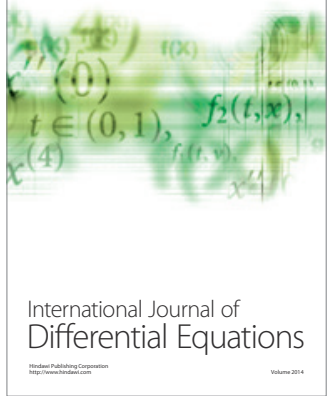
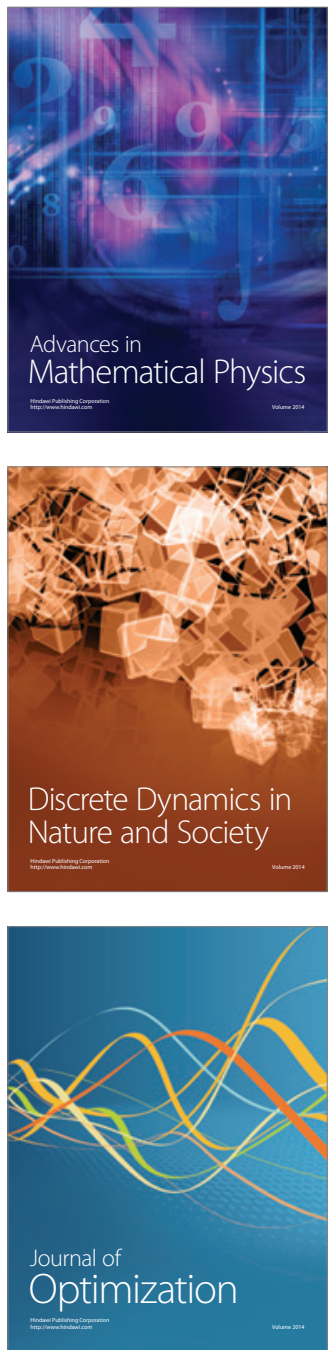